\title{
Políticas de saúde na empresa
}

Ernesto-Lima Gonçalves

Professor no Departamento de Administrafão Geral e Recursos Humanos, ADM, da EAESP/FGV.

\section{INTRODUÇÃO}

0 tema é relevante. Pesquisa realizada há algum tempo pela Associação de Dirigentes Cristãos de Empresas em São Paulo indicou que, do universo de 100 empresas cujas respostas foram tabuladas, $2 / 3$ consideram como não resolvido o problema da assistência médica a seus empregados; $40 \%$ delas mantinham contrato com grupos prestadores de serviços médicos, para atendimento a seus funcionários e respectivos dependentes. Das empresas que assim se pronunciaram, $10 \%$ foram além afirmando que o problema é grave, exigindo uma pronta solução.

Estes dados assumem maior profundidade, considerando-se que as 100 empresas referidas cobriam toda a gama de atividades empresariais urbanas - comerciais, industriais, prestadoras de serviços. Além disso, o porte das empresas consultadas também era bastante variado: desde as que contavam com até 100 funcionários, até aquelas com mais de 10 mil empregados.

\section{ASPECTOS CONCEITUAIS}

\subsection{O trabalho e o homem.}

A importância que o trabalho assume para o desenvolvimento da pessoa humana faz com que todos quantos se preocupam com esse crescimento tenham se ocupado das condiçбes em que se realiza o trabalho do homem.
Um resumo de tais reflexðes poderia ser o conhecimento de que o progresso material,' possibilitado pelo trabalho, está longe de ser um mal, podendo mesmo ser um grande bem. A razão é que ele é a expressão da inteligência humana, dominando a natureza e colocando-a a serviço da pessoa humana. Mas é forçoso lembrar que o trabalhö que seja dominado apenas por elementos e por diretrizes de natureza técnica levará à mecanização do homèm e, por consequêencia, da comunidade.

De outro lado, o trabalho submetido apenas à ditadura de princípios econômicos jamais conduzirá ao pleno desenvolvimento do homem. Este será apenas possível quando, ao lado de diretrizes técnicas e de princípios econômicos, o trabalho for regulado por imperativos de natureza ética. Será a obediência aos princípios técnicos, econômicos e éticos que permitirá a passagem de uma estrutura desumanizada para uma estrutura livre, variada e pluralista, desvinculada das exigências da necessidade e do arbítrio.

O processo técnico e econômico deve ser aceito como um bem, porque cria possibilidades mais favoráveis para o desenvolvimento material, intelectual, cultural $e$ espiritual do homem. Mas, para atingir esse amplo objetivo, o progresso deve ficar sob controle do homem. Para consegui-lo, será importante que a vida econômica seja organizada de maneira que todos, conforme a situação de cada um, possa participar ativamente das decisões que se adotam nesse campo de definições.

E fácil reconhecer que o homem, mesmo enquanto indivíduo, tem exigências básicas a serem satisfeitas, as quais não são, muitas vezes, sequer atendidas, em particular no contex to latino-americano.

Mas além desse mínimo individual existem dois aspectos complementares. $\mathbf{O}$ primeiro decorre de que $\mathrm{O}$ homem é naturalmente chamado a fundar uma família. E seu direito indiscutível, do qual decorrem, contudo, numerosas obrigaçōes ligadas à necessidade de prover os bens morais e materiais indispensáveis aos integrantes da nova unidade familiar. $\mathrm{O}$ segundo aspecto decorre das exigências que se colocam para o homem, na medida em que ele ultrapassa os limites de sua individualidade, para desabrochar como pessoa humana, marcada sobretudo pela racionalidade. Logo, enquanto pessoa, o homem tem a obrigação de desenvolver suas faculdades intelectuais e espirituais; para não se perder numa estagnação embrutecedora.

Em relaçđo ao homem - trabalhador na empresa -é essencial que se conservem a isenção e a lucidez suficientes para identificar que as sociedades industriais conseguiram satisfazer a quase todas as necessidades do consumidor, mas desenvolveram estruturas e condições de trabalho que põem em risco a realização das pessoas que a integram, sacrificando seu próprio dinamismo e vigor. Chega-se, assim, à situação de alienação em que o homem se encontra como um estrangeiro em sua empresa, em seu trabalho e até diante de si próprio. Argyris descreve a situação com palavras claras: "a fim de manter cotidianamente seu equilíbrio psicológico, dentro de um sistema industrial que exige que se comportem, não como adultos, mas como crianças, os trabalhadores terminam por capitular, tornando-se apáticos e indiferentes" (Argyris, 1957). Por sua formação e pela atividade que exerce, trata-se de autor que não se pode caracterizar como subversivo ou revolucionário. 
O principal mecanismo da capitulação mencionada prende-se ao esquecimento, pela direção da empresa, de que a realização pessoal de cada indivíduo exige o exercício de responsabilidade, o que se traduz pela participação na análise dos resultados da ação individual e grupal. Tal esquecimento gera um clima de insatisfação, que rapidamente se estende das pessoas aos conjuntos, formais ou informais, que convivem na empresa.

\subsection{Produtividade e motivação}

Nesse passo cabe lembrar que, na vida da empresa, os fatores de produção, representados pelas máquinas e pelas matérias-primas, são trabalhados pelos homens, com vistas à consecução dos objetivos da atividade empresarial. Nesse quadro, a maneira fundamental de maximizar os resultados da empresa é aumentar a quantidade dos fatores envolvidos, procurando ampliar sua produtividade. Em cada situação concreta, no caso das máquinas, habitualmente já se trabalha quase no limite máximo das possibilidades, representado pela sua capacidade nominal de produção. No caso dos homens, contudo, estima-se que, em geral, não sejam acionados mais do que $70 \%$ de suas potencialidades. Trata-se de indiscutível e inevitável consequềncia daquela capitulação, daquela despersonalização, daquele desinteresse, daquela desmotivação.

Chegamos aqui ao núcleo do problema. "A motivação é um capítulo novo e empolgante em administração e gerência. Seu interesse parece refletir um aumento de transição onde, de uma situação centrada na valorização da estrutura, da tecnologia e do mercado, passou-se a considerar o homem como fator primordial. Tal ênfase reflete-se como uma redescoberta, traduzindo os resultados de inúmeros experimentos que definem disfuncionamentos e perdas nas organizaçð̌es, como conseqüência da desmotivação humana" (Matos, 1980).

$\mathrm{O}$ aprofundamento da análise do tema - ainda que relevante - exigiria o exame da contribuição dos principais nomes da escola comportamentalista de administração empresarial, o que significa tarefa que não cabe nos objetivos deste texto. A simples enumeração dos tópicos mais importantes da contribuição que tais autores trouxeram servirá, contudo, para a verificação da total identidade entre os conceitos e posiçôes, que assumem esses competentes cientistas e frios administradores, com as exigências anteriormente expostas, relativas ao desenvolvimento individual e pessoal do homem.

A história talvez comece com Elton Mayo e suas célebres experiências na Western Electric; segue-se, com bom intervalo, a contribuição de Maslow, que hierarquiza as necessidades humanas e identifica que, embora os niveis sejam interdependentes e sobrepostos, não é indispensável satisfazer totalmente um nível para que surja a aspiração pelo outro.

Mais tarde, Likert demonstrou cientificamente a falsidade da pressuposição em que se baseia a teoria do alcance de controle, isto é, de que "os homens trabalham melhor sob estreita vigilância"; igualmente a partir da rejeição de conceitos negativos sobre a natureza e o comportamento humanos, caracterizados em sua teoria $X$, MacGregor elaborou o estilo de gerência mais adequado à motivação do homem e ao aumento da produtividade: trata-se da teoria $Y$. Herzberg identifica a motiva- ção com a possibilidade de os homens liberarem, no trabalho, sentimentos de realização, reconhecimento e crescimento profissional; para tanto, é necessário que a atividade laborativa lhes ofereça desafios, que representam fatores que provocam efeitos duradouros, gerando satisfação pelos resultados alcançados.

A lista de autores e a enumeração dos trabalhos poderia continuar. Mais importante, contudo, do que a teoria é a vivência prática de todos os dias que indica claramente a evidência de que atua do modo negativo na produtividade da empresa a mão-de-obra desestimulada pela indiferença da direção quanto aos problemas que afligem seus empregados. Entre tais problemas, um avulta como predominante: trata-se da insegurança decorrente da ausência de um esquema adequado de assistência médico-hospitalar, diante da doença grave ou do acidente sério, que atinge o próprio empregado da empresa ou um de seus familiares.

- $\dot{E}$ fácil compreender que essa insegurança gera profunda instabilidade emocional e perturba gravemente o desempenho do empregado, com prejuízo certo para a atividade empresarial.

Resta saber - sempre na linha da exploração dos conceitos - qual o significado ou a amplitude que deve merecer $o$ atendimento em questão.

\subsection{A saude integral do homem}

Acompanhando a evolução histórica dos conhecimentos sobre as doenças, é fácil compreender que as primeiras instituiçōes que se organizaram para ajudar os doentes em sua recuperação e, de alguma maneira, combater as doenças, apenas poderiam ser voltadas para a tarefa de diagnóstico e tratamento dos doentes; eram os hospitais. Aos poucos, foi possivel estender essa atuação até o nível de limitação do dano decorrente das doenças. Mas, por falta de conhecimentos, não havia como trabalhar nos hospitais em nível de prevenção primária das afecçōes. Contudo, mais tarde, mesmo conhecendo-se alguma coisa sobre a patogênese dos quadros clínicos, as instituiçбes hospitalares continuaram a se voltar essencialmente para o tratamento das doenças já instaladas, correspondendo ao que se denominou "medicina curativa", omitindo-se de participar de qualquer atividade destinada à prevenç̧̃ão das doenças.

A razão essencial é que, na medida em que progrediram os conhecimentos sobre os grandes agentes especificos e inespecíficos das doenças, outras agências de saúde foram sendo desenvolvidas, atendendo ao imperativo das necessidades da população. Trata-se daquele conjunto de instituições que foram se encarregando das tarefas que, por sua origem institucional, foram relacionadas com o que se denominou de "saúde pública". Essencialmente, eram e são tarefas que correspondem aos niveis de promoção e proteção da saúde e que, posteriormente, foram reunidas sob a denominação de "medicina preventiva". Por espírito da exagerada especialização e de injustificada rivalidade, tais instituiçōes jamais se comprometeram com tarefas assistenciais, que correspondessem às necessidades sentidas da população. Assim, nasceu e radicalizou-se o divórcio entre medicina "curativa" e "preventiva" no Brasil.

A experiência tem mostrado que o tratamento dos problemas relacionados com a saúde dos homens que 
integram a empresa pode ser fejto na mesma linha em que se desenvolve a análise dos problemas análogos envolvidos no atendimento à saúde de uma macrocomunidade, como a população de um estado ou de um país.

É útil lembrar aqui que a implantação, no Brasil, da legislação que instituiu a chamada medicina ocupacional representou um elo a mais no sentido de aperfeiçoar as estruturas legais e institucionais que regulam as relações de trabalho entre nós. Nesse sentido, os referidos dispositivos legais trouxeram uma contribuição positiva, que se somou a outros benefícios a que o trabalhador brasileiro já tinha acesso. Tal contribuição traduz-se, de um lado, por medidas destinadas a melhorar o meio ambiente em que o trabalhador desenvolve sua atividade; é o caso da redução de índices de poluição, de ruído ou de temperatura, da melhoria da ventilação ou da iluminação das oficinas ou dos locais de trabalho. Por outro lado, tal contribuição permitiu a caractẹrização das situações ou das condições em que é necessário interferir, para garantir a segurança do trabalhador, seja pela indicação do uso de equipamentos de proteção individual, seja pela modificação de condiçõés ou sistemáticas de trabalho, que pőem em risco a segurança e a integridade do operário.

Para a empresa, a legislação que ora analisamos trouxe a possibilidade de garantia em relação a riscos imprevisíveis. É o caso, por exemplo, da exigência de realização de exames médicos admissionais e periódicos. Medidas que, de um lado, representam a garantia de diagnóstico precoce de qualquer afecção no trabalhador e, de outro, a possibilidade de proteção da empresa contra os riscos de questões trabalhistas, envolvendo indenizações e pendências judiciais.

Aqui, porém, existe o risco de um novo equívoco, semelhante ao descrito na radicalização de posições rełacionada com atividades de "medicina preventiva" e de "medicina curativa". Trata-se da separação, tão artificial quanto essa, entre "medicina ocupacional" e "medicina assistencial". Esta separação pode conduzir aos mesmos inconvenientes já descritos quando se fez a análise das atividades preventivas e curativas, envolvidas no atendimento à saúde de uma comunidade. Por essa razão, aqui se propõe a implantação de uma política global de saúde para a empresa, que agregue os diferentes aspectos de natureza ocupacional e assistencial sob a denominação de um trabalho de "medicina integral".

Adotada tal política, será possível desenvolver-se adequado trabalho de planejamento, no qual, em nível crescente de detalhamento, será possível passar de planos para programas e projetos específicos. Cada um destes terá, naturalmente, objetivos gerais, metas definidas e quantificadas, indicação de órgãos, setores ou pessoas comprometidas, quantificação de recursos humanos ou materiais indispensáveis, definição de prazos de implantação e de desenvolvimento, indicação de instrumentos de avaliação e acompanhamento. Em conseqüência, será possivel preparar o orçamento global do serviço médico (SM), a partir de orçamentos dos planos, dos respectivos programas, com os correspondentes projetos.

E certo que uma política como a proposta irá exigir amplo trabalho de conscientização de toda a empresa, de que a ela cabe globalmente a responsabilidade pela saúde dos participantes da comunidade empresarial, em lugar de ser apenas uma atribuição do SM.
Será necessário trabalhar muito para criar uma nova mentalidade, mesmo entre os elementos do próprio SM, da qual resultará uma nova postura diante dos problemas de saúde dos empregados.

\section{ASPECTOS OPERACIONAIS}

Definidos os elementos de natureza conceitual, importa agora considerar como se pode operacionalizar aquilo que se tenha definido como prioritário executar, no campo da política de saúde na empresa.

Existem alguns esquemas básicos a que podem ser resumidas as diferentes formas de operar os serviços de atendimento à saúde no seio de uma empresa.

0 primeiro, certamente o que envolve menores compromissos, corresponde à utilização pura e simples dos recursos assistenciais do Inamps, completados por iniciativas próprias, no campo dos programas de medicina do trabalho, segundo definem as disposiçð̌es legais, em particular a Portaria no $3.214 / 78$ do Ministério do Trabalho, a qual aprova as Normas Regulamentadoras das Leis do Trabalho.

No que se refere às atividades de natureza assistencial, em que pese ao esforço das autoridades previdenciárias este esquema indiscutivelmente envolve o grave problema de uma demanda de serviços sem dúvida superior à respectiva oferta pela rede assistencial instalada.

Este fato é significativo, porque a grande e natural restrição que se faz ao atendimento oferecido por qualquer grupo prestador de serviços mé dicos - essência do segundo esquema que deveremos analisar - é o número obviamente limitado de suas unidades assistenciais instaladas. Em conseqüência, é possivel que o empregado, permanecendo sob a cobertura assistencial do Inamps, encontre mais próximo à sua residência o socorro médico que ele, ou seu familiar, precisaria procurar a distância considerável, na eventualidade de a empresa, firmando convênio com a Previdência, subestabelecer com algum grupo médico o compromisso de oferecer assistência médica a seus funcionários.

\subsection{Algumas alternativas possiveis}

Passamos dessa maneira do primeiro esquema para um segundo modelo possível, no qual a empresa decide não permanecer passiva: assume diante da Previdência Social, mediante celebração de um convênio específico, a responsabilidade pela assistência médico-hospitalar e odontológica a seus funcionários e dependentes, recebendo mensalmente daquela a devolução representada por uma quantia por empregado registrado, a qual é periodicamente reajustada pela Previdência Social; tal quantia varia segundo os compromissos que a empresa assume, os quais podem ser de cobertura global (ambulatorial e hospitalar) ou apenas ambulatorial.

A celebração de convênio desse tipo envolve algumas vantagens, mas também certas restriçōes. Entre as primeiras salienta-se a possibilidade de um atendimento mais fácil para o usuário, pelo uso de ambulatórios menos sobrecarregados do que os do Inamps; tal fato permite até alguma individualização no relacionamento médico-paciente. Para o lado da empresá, a decisão de participar ativamente do atendimento a seus empregados 
envolve - é natural - uma postura especial em relação à função social da empresa; tal postura, se traduzida em soluções adequadas, irá conduzir a uma integração positiva dos participantes da comunidade empresarial, aumentando-lhes o nível de satisfação, o que se concretiza quase sempre em incremento da produtividade da empresa. Além disso, assumindo as responsabilidades pelo atendimento à saúde de seus empregados, a empresa passa a dispor de melhores controles médicos e administrativos, sobretudo aqueles relacionados com certos pontos críticos, como o ausentismo.

Mas existem também algumas restrições à celebração de um convênio como o referido. Uma, de ordem geral, corresponde à interferência do Inamps na vida da empresa, traduzida nas exigências burocráticas, nas inevitáveis atividades de fiscalização. Outras restrições, de caráter setorial, prendem-se à solução que a empresa venha a adotar, para atender às responsabilidades que assume, ao firmar o convênio com a Previdência Social. Duas opções principais existem a esse respeito: a contratação de uma entidade prestadora de assistência médico-hospitalar, à qual a empresa transfere as responsabilidades que assumiu, ou o desenvolvimento do serviço médico próprio, com o qual irá atender a tais responsabilidades.

A alternativa representada pela contratação de um grupo ou entidade prestadora de serviços assistenciais compreende algumas objeçðes essenciais. A primeira foi formulada quando, anteriormente, foi lembrado o número naturalmente limitado de unidades assistenciais de que cada entidade dispõe; é fácil imaginar os prejuizos que daí decorrem. Outra crítica é representada pela possibilidade - sempre presente - de que a manutenção de margem de lucro definida pela direção da entidade possa envolver sacrifício da qualidade dos serviços assistenciais prestados; entende-se que, trabalhando com contrato em que a receita é fixada por considerável período de tempo, a solução para maximizar ou pelo menos manter o lucro será a redução compulsória da despesa. Ainda uma objeção a esse sistema é que se trata de iniciativa que envolve atividades consideradas antiéticas pelos órgãos de classe e de avaliação da atividade médica.

A segunda alternativa é tepresentada pela prestação de assistência médico-hospitalar pela própria empresa ou por alguma entidade complementar a ela vinculada sob o ponto de vista administrativo e organizacional; também aqui existem diferentes obstácúlos. Alguns são de ordem puramente administrativa, correspondente à organização de um serviço médico próprio, mas os maiores são de natureza financeira, uma vez que a adoçăo desse sistema faz com que todos os encargos de manutenção do esquema assistencial recaiam sobre a empresa; a razão é que o convênio com o Inamps veda a participação do empregado no custeio do atendimento. Tal exigência é coerente com o espírito com que a Previdência Social criou os chamados "convênios de empresa", traduzido no fato de que os empregados deverão continuar a receber pelo me nos o mesmo atendimento que o Inamps thes oferece, nas condiçбes de gratuidade que marcam 0 atendimento previdenciário. É por/essa razão que a Previdência Social tem procurado estimular a execução de tais convênios; basta lembrar que, ao longo do tempo, foi ela retomando - no quadro dos convênios implantados - cada vez maiores responsabilidades nos tratamentos complexos ou de al to custo; cirurgia cardíaca com circulaç̧̃o extracor- pórea ou hipotermia profunda; neuromicrocirurgia na cavidade craniana; trạsplantes e implantes de órgãos; tratamento ambulatorial e internações nos casos de tisiologia; internações em hospitais psiquiátricos; tratamentos e/ou operaçōes cirúrgicas de custo elevado.

\subsection{Uma solução integradora}

A impossibilidade de participação do empregado no custeio do modelo médico-assistencial que venha a ser definido merece uma análise mais cuidadosa. Toda a modema teoria de administraçăo de empresas aponta para o futuro com uma visão comunitária da atividade empresarial, onde todos os integrantes sintam-se verdadeiramente integrados em todos os aspectos da vida da empresa: nos objetivos, nas políticas, nas práticas, nos compromissos, na vida de todo dia. Como homens, sentem-se realizados quando participam, mas permanecem infantilizados quando são mantidos à margem dos processos envolvidos na atividade da empresa. No primeiro caso, sentem-se motivados e produzem mais, porque se sentem tratados como pessoas; no segundo, permanecem indiferentes e apáticos, cumprindo apenas rotineiramente suas tarefas. Entre as vias de integração do empregado na vida e nas preocupações da empresa, duas devem ser salientadas: uma é representada pela tomada de sua opiniăo a respeito dos assuntos de natureza empresarial que the dizem respeito; afinal o homem é o único ser da natureza capaz de pensar e de amar, o que supõe e exige diálogo, possibilidade de emitir opiniōes e juízos. A segunda via de integração é a participação, inclusive material, nas realizações e realidades da empresa.

Essa é a razão fundamental que originou o terceiro esquema referido inicialmente: sem fazer convênio com a Previdência Social, a empresa assume a iniciativa de organizar um esquema de assistência médico-hospitalar. Conserva-se, dessa maneira, integral autonomia para solicitar a participação do empregado, tanto na elaboração do modelo quanto no seu custeio. Naturalmente, deixa de haver a devolução mensal do Inamps, por inexistência de convênio. Em compensação, existe menor ingerência da Previdência na vida da empresa e mantém-se a cobertura previdenciária para os casos de maior complexidade ou que interessem ao esquema assistencial que venha a ser desenvolvido pela empresa.

Tanto na eventualidade de se celebrar convênio com - Inamps, quanto na decisão de a empresa desenvolver seu modelo próprio, sob sua exclusiva responsabilidade, existe um esquema de operação que vem sendo crescentemente adotado. Trata-se de a empresa, por seu setor especifico, entrar em contato com profissionais e entidades prestadoras de serviços assistenciais, credenciando-os para atender, em seus próprios consultórios e em suas próprias instalaçðes, os doentes que lhes sejam encaminhados ou que os procurem diretamente, conforme definição que venha a ser adotada. Tal procedimento agiliza de maneira considerável o atendimento, uma vez que cada consultório particular, clínica ou hospital passa a funcionar como verdadeiro ambulatório a serviço do esquema adotado pela empresa. Do outro lado, na seleção dos profissionais ou entidades assistenciais poderá haver prévia consulta aos empregados, 'o que já responde a um dos elementos de integração analisado. 
Tal como foi descrito para a opção correspondente ao primeiro esquema de atendimento possivel - utilização pura e simples dos recursos assistenciais do Inamps também no segundo e terceiro esquemas descritos a parte "assistencial" deverá ser completada, de acordo com as determinações legais, com a organização de serviços de medicina do trabalho. Por essa razão, estarão convivendo agora no seio da empresa iniciativas voltadas de algüma maneira para a saúde do empregado. Importa, então, que não correspondam elas a atividades paralelas $\mathrm{e}$ desintegradas, que chegam às vezes a ser concorrentes e conflitantes. A qualquer custo deve-se buscar que, ao contrário, desenvolvam-se de maneira in tegrada, uma vez que seu objetivo é comum. $\mathrm{O}$ gerenciamento de todo esse conjunto de idéias tem sido analisado em outras publicações (Lima Gonçalves, 1980; Lima Gonçalves \& Quaglia, 1980).

\subsection{Hipóteses complementares}

Duas idéias complementares podem, ainda, ser acrescentadas, quanto à operacionalidade dos esquemas que envolvam a responsabilidade direta das empresas. A primeira responderia ao problema representado pelo porte limitado de empresas interessadas. Nesse caso, para fugir a uma eventual deseconomia de escala, existe a possibilidade da associação de serviços congêneres, caso em que o intercâmbio de atendimento propiciaria custos mais reduzidos, associados a um padrão de qualidade elevado. Dessa forma, serviços que possuam recursos complementares, como laboratório e radiologia, com capacidade ociosa poderiam associar-se a outros, com benetícios mútuos evidentes. Nessa linha poder-se-ia até pensar na criação de serviços auxiliares ou hospitais colocados à disposição de várias empresas com assistência médica própria.

A outra idéia refere-se, ao contrário, a empresas ou conglomerados empresariais de grande porte, muitas das quais dispōem de entidades auxiliares, do tipo de fundações, para executar programas complementares aos da Previdência Social, referentes a planos de benefícios. Tais entidades funcionam como instituições fechadas de previdência privada, cuja atividade é regulada basicamente pela Lei n? $6.435 / 77$, com decretos, portarias e resoluções a ela relacionados. De acordo com tais documentos legais as fundações referidas não podem executar sob sua responsabilidade financeira programas assistenciais; por essa razão, têm sido encarregados, muitas vezes; de gerenciar tais programas em nome das empresas mantenedoras, que continuam a responsabilizar-se financeiramente por essas iniciativas. Contudo, o II Congresso Brasileiro de Entidades Fechadas de Previdência Privada, realizado em Brasflia em outubro de 1980, inseriu em suas conclusões a imperiosa necessidade de que os textos legais indicados fossem alterados, a fim de que tais entidades pudessem desenvolver, com maior amplitude, programas de natureza assistencial, notadamente no campo da saúde. No encerramento do III Congresso Nacional organizado pela mesma entidade em novembro de 1981, o secretário-geral do Ministério da Previdência e Assistencia Social, revestido da autoridade de ministro interino da mesma pasta, afirmava que "parece-nos ser (chegado) o momento de aprofundar também as linhas de atuação que venham a situar as entidades fechadas de previdência privada na perspectiva daquilo que poderá fazer com que, pela ampliação gradativa de seu número e pelo alargamento do espectro de atividades, venha possibilitar à previdência social estatal ser mais e mais liberada para o aperfeiçoamento da atenção que deve dar, prioritariamente, às classes menos favorecidas" (ABEFPP, 1981).

\section{ASPECTOS FINANCEIROS}

Examinados os aspectos conceituais e operacionais mais importantes, relativos ds políticas de saúde na empresa, resta examinar alguns outros ângulos do problema, referentes ao custeio e aos custos dos programas correspondentes.

Celebrado o convênio com a Previdência Social, os encargos que superam o valor da devolução da Previdência recaem sobre a empresa, uma vez que é vedada, nessas condições, a possibilidade de solicitar ao empregado qualquer participação. Dessa forma, tanto opte por contratar uma entidade prestadora de serviços assistenciais quanto se decida por desenvolver seus serviços próprios, a empresa terá os correspondentes custos financeiros. A situação, contudo, é sempre diferente num e noutro caso, particularmente em relação aos custos sociais correspondentes. No caso da contratação de uma entidade prestadora de assistência, tais custos tendem à ser altos, representados pela insatisfação dos empregados, em grande número de oportunidades. Por este caminho, voltamos ao problema da motivação e da produtividade, analisados em item anterior. No caso dos serviços próprios, tais custos sociais tendem a ser menores, uma vez que as reclamações e sugestões dos usuários são apresentados diretamente aos setores específicos da empresa, que podem, então, adotar as correçōes indispensáveis. Ao lado disso, pode a empresa desenvolver eficiente controle da qualidade dos serviços desenvolvidos, mesmo quando executa os atendimentos com a colaboração com alguns serviços assistenciais credenciados.

\subsection{O significado da participacão do empregado}

Quando a empresa prefere não celebrar convênio com a Previdência Social, permanece liberada para solicitar a seus empregados alguma forma de participação no custeio dos programas assistenciais desenvolvidos. Não se trata aqui de reduzir os encargos da própria empresa ou de simplesmente introduzir um fator de moderação na utilização dos serviços oferecidos. Em toda parte do mundo, caminha-se para uma reformulação no conceito do que significa a empresa, enquanto comunidade humana que indiscutivelmente ela é. Por toda parte desabrocha a idéia de que, formada por pessoas humanas, a empresa deve oferecer a $\backslash$ cada um de seus integrantes a possibilidade de se realizar plenamente. No caminho de sua realização no trabalho está a atribuição de responsabilidades, no campo da atividade laborativa do empregado, mas está igualmente a contribuição a tarefas e encargos de interesse comum que a empresa desenvolve. Aqueles que, com alguma superficialidade ou muita distância dos modernos enfoques e tendências da administração empresarial, condenam a solicitação de tais contribuiçбes deveriam deter-se por um momento e procurar 
refletir sobre as verdadeiras razбes que justificam o procedimento. Sobretudo, que se reconheça que não existe, por parte de todas as empresas que assim começam a proceder, o intuito de desenvolver mais um instrumento de exploração do trabalhador; pelo contrário, em muitas delas existe exatamente o interesse de contribuir para o desenvolvimento de uma comunidade humana realmente integrada.

A forma mais simples de se implementar essa participação dos empregados no custeio dos programas assistenciais desenvolvidos será definir um percentual fixo sobre o salário, a ser descontado de todos, igualmente. natural que, em termos de unidades monetárias; 0 valor desse desconto será tanto maior quanto maior for o salário do empregado. Existe aqui, contudo, um duplo inconveniente: de um lado, a dificuldade de se definir o percentual de desconto que deve incidir sobre os salários, uma vez que não é tão simples calcular previamente o cuisto total do programa assistencial definido; está claro que um estudo atuarial adequado, levando em conta diferentes variáveis da comunidade a ser atendida, poderá estimar esse total com alguma aproximação, embora possa existir uma apreciável margem de erro nesses cálculos. De outro lado, existe nesse procedimento uma discreta forma de implementar um esquema de injustiça social, ou seja, tratar igualmente os desiguais; trata-se de comportamento tão pouco adequado quanto o que consiste em tratar desigualmente os iguais.

Por esse duplo inconveniente dá-se, em geral, preferência a um esquema que consiste em definir um percentual de participação do empregado no custeio dos atos assistenciais prestados a ele próprio ou a um de seus dependentes; com isso se contorna a dificuldade de se esti. mar previamente o custo total do programa. 0 esquema poderá ser aperfeiçoado com a definição de percentuais diferentes de participação do empregado, inversamente proporcionais ao valor dos salários recebidos; dessa maneira, estaremos tratando os desiguais desigualmente, na proporção de sua desigualdade. Esse é o esquema adotado em numerosas empresas, entre as quais o metrô de São Paulo.

Na linha de um aperfeiçoamento social crescente, pode-se levar em conta, não apenas o valor do salário que o empregado recebe, mas relacioná-lo com os encargos familiares que oneram esse salário. Trata-se de criar uma tabela de participação em que pagarão menos aqueles que recebem salários mais baixos ou têm maior número de dependentes. Esse é o esquema de participação implantado em diversas empresas, entra as quais a Cosipa.

\subsection{O problema dos custos financeinos}

Analisados assim os aspectos mais significativos referentes ao custeio dos programas do atendimento à saúde dos integrantes da empresa, vale a pena examinar alguns elementos referentes a seus custos. Diante da diversidade de esquemas assistenciais possíveis, não é fácl traçar um quadro bem definido do assunto. Deliberadamente, ño iremos tentar aqui a definição do custo relativo a contratação pela empresa de uma entidade prestadora do serviços assistenciais, a fim de se desincumbir dos compromissos decorrentes da celebração de convênio com a Previdência Social. A razão é que, tratando-se de atividade vinculada as leis do mercado em que tais entidades operam, os valores alteram-se muito, em função de diversas variáveis de difícil definição prévia, para uma tentativa de colocação geral. Em conseqüência, iremos examinar os custos relativos a esquemas assistenciais desenvolvidos sob responsabilidade direta da empresa, seja exclusivamente por meio de seus serviços médicos próprios, seja por meio de recursos externos credenciados.

Uma apreciação a esse respeito exige a utilização de diferentes indicadores: percentagem do custo sobre 0 valor da folha de pagamento; custo mensal por empregado e por usuário; percentagem do custo da assistência odontológica e da assistência farmacêutica em relação ao custo da assistência médico-hospitalar; custo do esquema administrativo sobre o custo total do plano assistencial e sobre o custo da assistência médico-hospitalar. Os quadros 1 e 2 procuram resumir a experiência de algumas empresas, que adotam diferentes esquemas assistenciais, utilizando-se os indicadores referidos.

Quadro 1

Indicadores do custo total do programa e da assistência médico-hospitalar

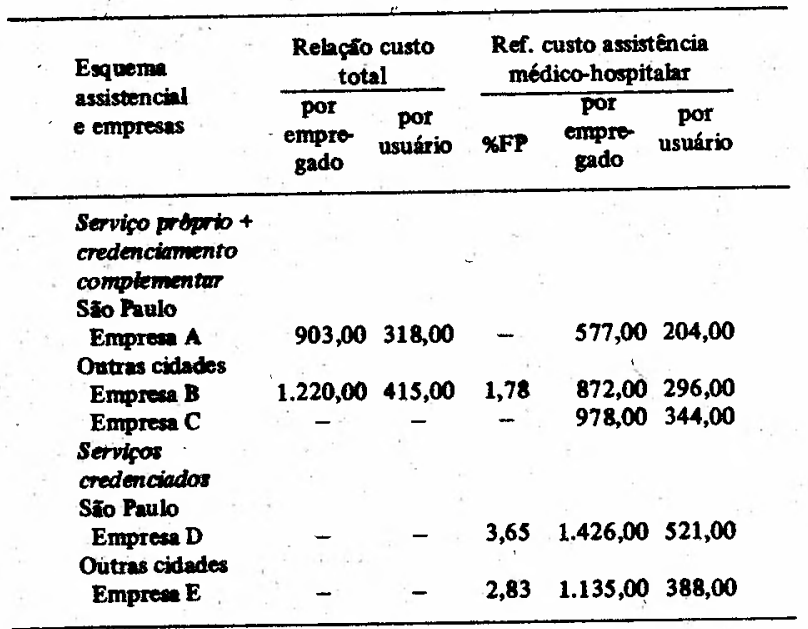

Quadro 2

Indicadores do custo da assistência odontológica e farmacêutica e do sistema administrativo adotado

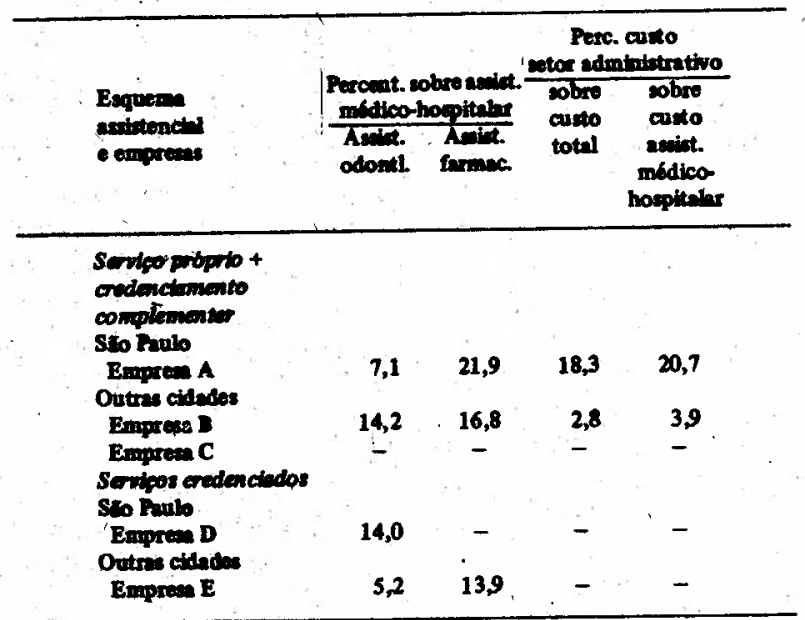

As informaçð̃es incompletas relativas às empresas $C$; , $D$ e $E$ derivam do fato de que a assistência odontológica e farmacêutica que oferecem não obedecem ao mesmo esquema de custelo que a assistência médico-hospitalar. 
A análise desses quadros permite várias observaçð̃es, a primeira das quais se refere à diferença entre os custos dos diversos modelos; em princípio, observa-se que os custos são menores naquelas empresas. que se estruturam sobre serviços assistenciais próprios. Aqui vale a pena insistir sobre dois fatos: o primeiro é que naturalmente não figuram no levantamento apresentado os custos de implantação - construção de instalaçồes e aquisição de equipamentos - muito elevados dos referidos serviços médicos próprios. O segundo fato é que esta alternativa exige a montagem de um considerável esquema administrativo, como se observa nos dados correspondentes à empresa $A$.

Quanto às empresas que preferem organizar-se em termos de serviços credenciados, observa-se que seus custo são mais elevados do que nos outros casos; em compensação, não existem custos de implantação $e$ as despesas administrativas são menores. A diferença observada no custo da assistência odontológica resulta do fato de que nas empresas $A$ e $E$ ela é oferecida apenas aos empregados, enquanto que nas empresas $B$ e $D$ o programa é estendido aos dependentes.

Existe um aspecto relevante na atividade das empresas que dispð̄em de serviço médico próprio; trata-se da possibilidade do mais rigoroso controle dos custos, nas diferentes atividades desenvolvidas, em particular na execução dos serviços complementares de diagnóstico e tratamento.

\subsection{Uma possibilidade de cooperação empresa-Estado}

Um último elemento relativo ao custo dos programas assistenciais merece ser considerado; trata-se das responsabilidades globais que a empresa recebe, quando se decide a assumir a parcela de encargos sociais representada pelo atendimeno à saúde de seus empregados e respectivos dependentes. Em função do que foi exposto, uma parcela dos custos totais pode ser coberta, seja pela dévolução da Previdência Social na hipótese de ser celebrado o convênio correspondente, seja pela participação dos empregados, possível na eventualidade de tal convênio não se concretizar. De qualquer maneira, os encargos que a empresa absorve são da ordem de 70 a $75 \%$ dos eustos totais do programa, o que representa um investimento apreciável.

Considerando-se a elevada significação social que assumem tais programas, mas principalmente a elevada colaboração que eles representam para o desafogo dos serviços assistenciais que o poder público deve, por determinação legal, oferecer, será muito razoável que se desenvolva uma revisão no papel que o Estado, a empresa e a comunidade desempenham diante do problema.

Em tópico anterior deste trabalho foi referida a dupla possibilidade de que a empresa dispõe para desenvolver as tarefas que estamos analisando: executá-las integralmente por meio de seus setores específicos ou atribuir sua execução a entidades complementares - quando elas existem - que já exercem outros programas oferecidos aos empregados; a figura mais freqüente neste último caso é de uma entidade fechada de previdência privada.

A revisão que se deseja e se espera refere-se a um apoio do Estado, de natureza financeira, o qual poderia ser exercido de acordo com uma ou outra das possibilidades analisadas. Assim, quando a empresa executa os programas assistenciais por meio de serviços próprios, os encargos correspondentes deveriam merecer o mesmo tratamento atribuido aos programas de alimentação e de treinamento desenvolvidos pelas empresas. Estes últimos foram estimulados e desenvolvidos de maneira cada vez mais abrangente a partir do momento em que foram estabelecidos apreciáveis incentivos fiscais para a sua execução. $O$ beneficiado foi o trabalhador brasileiro e, em conseqüência, a comunidade, que passa a dispor de homens mais capacitados e melhor alimentados. Adotada a proposta aqui examinada, certamente disporia a comunidade brasileira de um importante instrumento para a elevação do padrão de saúde de seus integrantes.

No caso de a empresa atribuir os programas assistenciais que se decide a desenvolver a uma entidade complementar, será essencial que se modifique o texto da Lei no 6.435, que regula o funcionamento das referidas entidades fechadas de previdência privada. Como já se analisou, o referido instrumento legal proibe que tais entidades participem do custeio de programas assistenciais; a posição do legislador foi provavelmente marcada pelo interesse em preservar as reservas financeiras indispensáveis ao pagamento dos benefícios pecuniários que as referidas entidades devem garantir. $\mathrm{O}$ exemplo do que ocorreu com o INPS é recente e eloqüente: é indiscutivel que uma das raizes das dificuldades financeiras que a Previdência Social estatal vem enfrentando prende-se à aplicação de considerável parcela de suas reservas em gigantescos empreendimentos de responsabilidade do governo federal, mas cujos objetivos nada têm a ver com benefícios e programas previdenciários.

Deve-se considerar, como importante elemento para desenvolvimento de um raciocínio lógico, o fato de que a estimativa para fins de 1982 é de que as reservas financeiras acumuladas das entidades fechadas de previdência privada devem aproximar-se de Cr $\$ 1.500$ bilhões - ou seja, Cr\$ 1 trilhão e meio. Trata-se de expressiva poupança acumulada ao longo de anos por integrantes das comunidades empresariais brasileiras e que representa motivo de atenção no atual contexto financeiro nacional. Estabelecidos rígidos parâmetros de execução, colocados limites operacionais adequados, criados esquemas de responsabilização pessoal e funcional, a atitude inteligente do administrador e do legislador será a de buscar a adequação do texto legal às necessidades emergentes. Nesse sentido, é que a referida Lei no 6.435 merece ser examinada e ter seu conteúdo modificado, possibilitando a execução de programas assistenciais por tais entidades, a fim de que os responsáveis diretos pela geração da riqueza nacional - aqueles que operam e fazem operar todas as empresas brasileiras - desfrutem, pessoalmente e através de seus dependentes, dos resultados da poupança que ajudaram a acumular.

Uma possibilidade, talveż até mais simples de ser implementada, é de que as empresas que decidem participar do esforço nacional em benefício da saúde do homem brasileiro, desenvolveñdo serviços médico-assistenciais próprios, deveriam merecer do poder público, representado pela Previdência Social, uma consideração à parte. Em outras palavras, deveriam elas merecer a celebração de convênios especiais, distintos dos simples "convênios de empresa", que permitem o subestabelecimento de compromissos assumidos. Trata-se de iniciativa 
que já tem precedentes e que não ficaria ligada, como no caso dos incentivos oferecidos aos programas de treinamento e de alimentação, à margem de lucro da empresa.

\section{REFERENCIAS BIBLIOGRAFICAS}

Argyris, C. Personality and organization. New York, Harper \& Row, 1957.

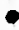

Associaçăo Brasileira de Entidades Fechadas de Previdência Privada. Anais do III Congresso Brasileiro. São Paulo, 1981.

Lima Gonçalves, E. Uma política de saúde para a empresa - II. Revista Brasileira de Saúde Ocupacional, 8: 52-6, 1980.

\& Quaglia, S. R. Uma política de saúde para a empresa - I. Revista Brasileira de Saúde Ocupacional, 8: 39-42, 1980.

Matos, F. G. Gerência participativa. Rio de Janeiro, Biblioteca do Exército, 1980.

\section{ONDE QUER OUE VOCÊ ESTEJA CHEGAMOS ATÉ VOCE \\ LIVROS E PERIÓDICOS DA FGV PELO REEMBOLSO POSTAL}

\section{Pedidos da:}

Fundaçấo Getulio Vargas/Eutiora

Divisäo de Vendas

Caixa Postal 9052

20000 - Rio de Janeiro

$R J$

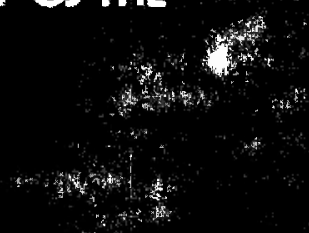

